\title{
Feasibility Study of Hybrid Wind-Diesel-Battery Power Generating Systems: Parametric and Sensitivity Analysis
}

\author{
Hussein Ibrahim \\ InstitutTechnologique de Maintenance Industrielle \\ (ITMI), Cégep de Sept-Îles, 175 rue de la Vérendrye Sept- \\ Îles (Québec) G4R 5B7, Canada \\ hussein.ibrahim@itmi.ca
}

\author{
Mazen Ghandour, Georges El-Jamal \\ Faculty of engineering III, Lebanese University, \\ Université Saint-Joseph, \\ Beirut, Lebanon \\ drmazengh@yahoo.com,gfjamal@yahoo.com
}

\begin{abstract}
The renewables energies are being used to reduce the environmental pollution, combat the climate change and burning of fossil fuels. For remote or decentralized areas, where grid connection is very complex, renewable energy generation system can be a reliable and optimized source of energy. Moreover, wind-diesel-solar hybrid system technology promises lots of opportunities in remote areas which are far from the main grid and are supplied by diesel gensets. This paper is based on the analysis of a hybrid energy system for optimization. The analysis of the hybrid system is realized in the HOMER software package. The HOMER software was utilized as the assessment tool with modeling performed with hourly data of wind speed, solar radiation and load. In this study, the remote village of Tuktoyaktuk situated in Northwest Territories of Canada has been taken for the discussion of the optimization analysis of a hybrid energy generation system.
\end{abstract}

Keywords - Hybrid power systems; renewables energies; wind energy; solar energy; batteries; optimization; sensitivity analysis; HOMER.

\section{INTRODUCTION}

Many peoples in the world live in isolated and rural areas not connected to the main utility grid. It is very complex their supply by the distribution grid because of the high cost of transport and the distribution of energy to this remote areas [1]. The electric provisioning of these sectors is done by diesel generator systems [2]. However, this option is becoming obsolete due to high operating cost, issues of fuel transportation and environmental concerns. With increasing of the penetration of renewable energy technologies into the power market, remote area hybrid energy systems (RAHES) are considered as interested solutions to supply remote and regional areas [3]. Usually, RAHES systems consist of one or more renewable energy technologies with conventional generation schemes such as diesel [4]. The integration of conventional generating technologies to a RAHES system is fundamental due to uncertainties related to renewable sources, low inertial support and less reactive power support from renewable power plants [5]. However, to enhance the efficiency and profitability of the system, the part of the conventional power plant (ie. diesel generator) should be kept at a minimum [4].
Depending on the availability of resources, an appropriated generation mix can be envisaged to form a RAHES system. In the past, the hybrid systems have been considered as preferred for remote systems like radio telecommunication, satellite earth stations, or at sites far away from a conventional power system [6-9]. Today, there is a trend to update the existing one source system (PV, wind or hydro) into hybrid system [10].

The choice of renewable energy (RE) resources for such a power system is entirely dependent on the availability of the resources such as sun and wind. Among all these RE options, wind is classified as the fastest growing renewable energy technology in the energy industry [4].

Wind-diesel hybrid systems (WDHS) significatly reduce the need for storage of fuel, cost of fuel consumption, and greenhouse gas emission as opposed to their conventional diesel only counterpart. With increasing introduction of wind turbines in WDHS, system stability is becoming a crucial issue to the power supplier. Indeed, the variable, stochastic and erratic characteristics of wind energy create several problems when a wind generating system operates in its standalone operation mode that may lead to frequency and voltage perturbations [11-12]. The most difficult issue is to assess the capacity adequacy of the hybrid system in addressing the electricity demand of the consumers. However, the well-developed techniques applied to conventional generation system reliability evaluation, associate fixed capacity outputs to generating units and cannot be readily extended to include wind energy sources that have highly fluctuating capacity levels.

Therefore, it is necessary to integrate an energy storage system (ESS) to improve the performance of such a power system [11]. The power mismatch between generation and demand can be delivered or stored using an ESS system.

When selecting an ESS system for a remote hybrid energy system, the ESS technology, efficiency, reliability, cost, autonomy, and rating of the ESS are the most important factors to be considered. Among the different energy storage technologies available, battery can be considered as the most appropriate energy storage option for an autonomous power system due to its high energy density capacity [13]. A dump load also plays an important role in a RAHES system. In a real 
RAHES system, a dump load can be a space heater or a water heater that absorbs the excess of energy which cannot be utilized by an ESS.

\section{REMOte AREA HYBRID ENERGY SySTEM DESCRIPTION}

The RAHES system considered in this paper which consists of a wind power plant, main loads and dump load, battery storage system, diesel power plant, and its controller, is shown in Figure 1. It is important to mention that the control algorithm is not presented in this paper because the main objective of this work is to conduct a sensitivity and parametric study of the RAHES. However, we assume that the active power of the system has been controlled with objective to minimize the imbalance of the RAHES's active power while extracting maximum power from wind turbines.

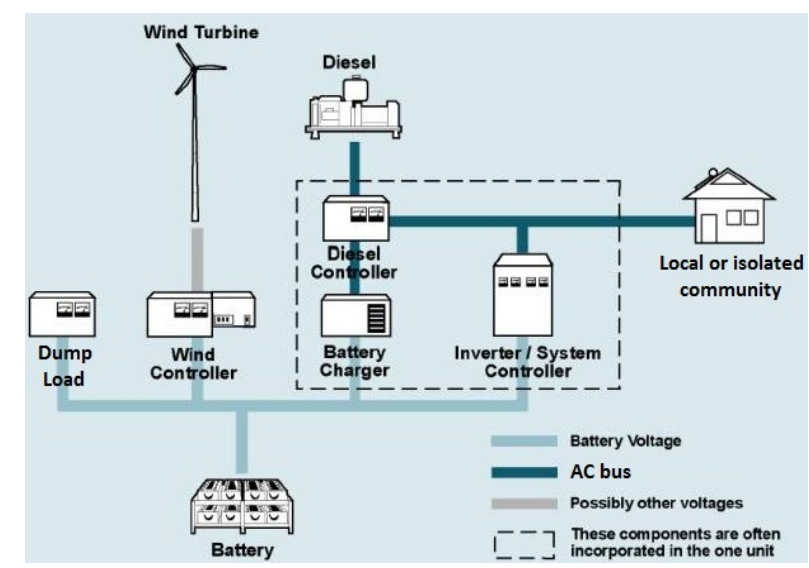

Figure 1: Schematic of remote area hybrid energy system [14].

In the present work, HOMER Micropower Optimization Model was used to conduct the designing, sensitivity and parametric study and techno-economic analysis of winddiesel-battery hybrid systems. HOMER is general purpose hybrid system design software that facilitates design of power systems for stand-alone applications.

\section{HOMER MICROPOWER OPTIMIZATION MODEL}

The Hybrid Optimization Model Energy Resource, otherwise known as HOMER, is a computer model tailored for the simulation of hybrid power systems. Originally designed at the National Renewable Energy Laboratory (NREL) for the village power program, HOMER is now licensed to HOMER Energy [15]. HOMER simplifies the task of evaluating designs of both grid-connected and off-grid power systems for several applications. HOMER is a software that designs the most optimized and cost effective hybrid energy system component configuration after a long series of hourly simulations considering some parameters and component prices. The wind speed data, solar radiation data, load profile, prices of the system components have to be provided to the software.

HOMER achieves hundreds of hourly simulations to ensure the best possible matching between supply and conception in order to design the optimum system [16]. To analyse the effect of modifications of some parameters such as, wind speed variation, solar radiation, PV investment cost variation and diesel fuel price variation on the optimum result, sensitivity analysis can also be done. HOMER simulates the operation of a system by making energy balance calculations for each of the 8,760 hours in a year.

For each hour, HOMER compares the total demand (thermal and electric) in the hour to the energy that the system can supply in that hour, and calculates the energy flows to and from each component of the system [17].

For systems that include conventional generators or batteries, HOMER also decides for each hour how to operate the generators and whether to charge or discharge the batteries. After simulating all of the possible configurations of the system, HOMER displays a list of configurations, classified by lifecycle cost (LCC) that can be used to compare the different design options of the system [17].

Simulation, Optimization and Sensitivity analysis are the three major actions run by HOMER. In the simulation process, different power system configurations for every hour of the year are generated with their technical feasibility and LCC [18]. In the optimization process, HOMER selects one system configuration out of all configurations generated in the simulation process that satisfies all technical constraints and has the lowest LCC. In the sensitivity analysis, multiple optimizations are achieved on the selected configurations by Homer with a range of parameters that are supposed uncertain and there can be affect the model inputs with time. For the different variables known to the system designer- that is, the mix of system components and their respective quantity and size - the optimization process allows to calculate the optimal value. There are, however, also unknown factors such as uncertainties or changes in the variables outside the designer's control (for example, the average wind speed, rises in the fuel price or). The effects of these can be analysed with the help of the sensitivity analysis [18].

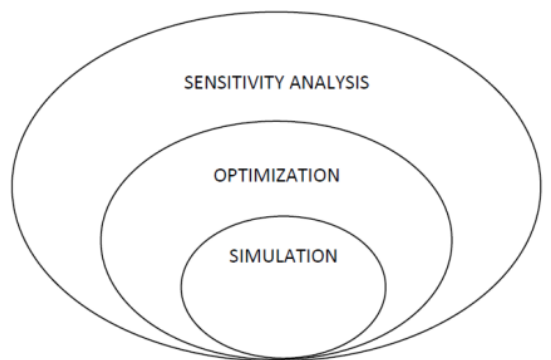

Figure 2: Relationship between simulation, optimization, and sensitivity analysis in HOMER [19].

Figure 2 shows how simulation, optimization and sensitivity analysis are interrelated. The oval figure enclosed in another oval figure shows that one optimization consists of multiple simulation and one sensitivity analysis consists of multiple optimizations.

\section{IV.PHYSICAL MODELING AND SYSTEM INPUTS}

This section provides details about the physical operation that HOMER models for its simulation process.

The subsections describe the diverse input parameters HOMER requires to model the system: the chosen energy 
components to produce electricity, the energy demand (village load) that the system has to serve, the various energy resources associated to the selected components, and how this hybrid configuration operates to supply the loads.

\section{A. Electrical load}

In this study, the data of electrical load are taken for the village of Tuktoyaktuk situated on the Arctic Ocean in the extreme north of Canada's Northwest Territories. The average electric load of Tuktoyaktuk is $506 \mathrm{~kW}$ while its maximum load is about $851 \mathrm{~kW}$.

\section{B. Wind Resource}

Accurate wind speed data is primordial to the precision of any wind-diesel hybrid system model. The data used in the HOMER simulations was registrated between January and December 2007. The characteristics of the wind speed throughout the year can be observed from the figures 3 and 4 . Figure 3 shows the variation of the monthly wind speed in the site (Tuktoyatuk village). In addition, the wind speed variation over a period at the site is described by the probability density function (Weibull distribution) shown in Figure 4.

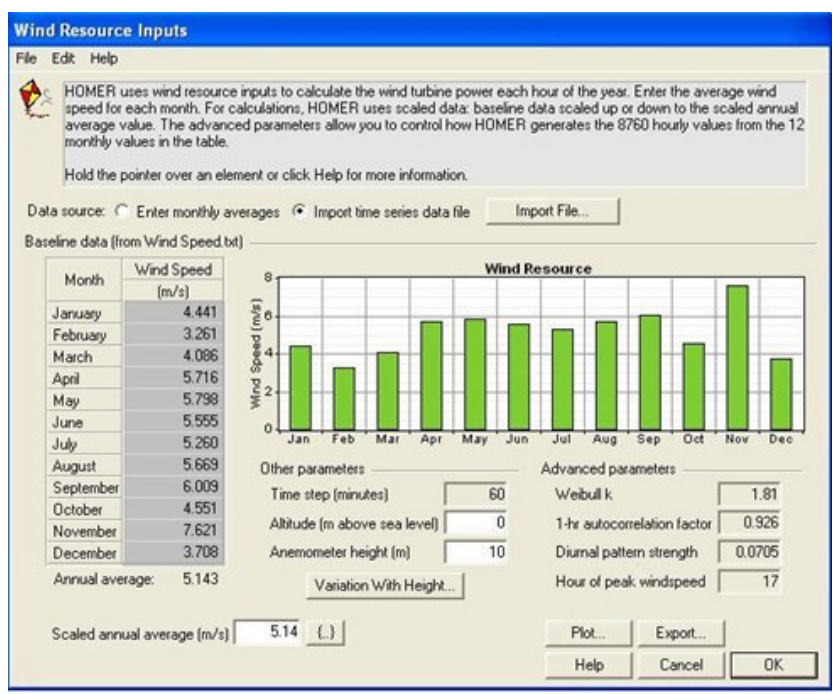

Figure 3: Wind speed data throughout the year.

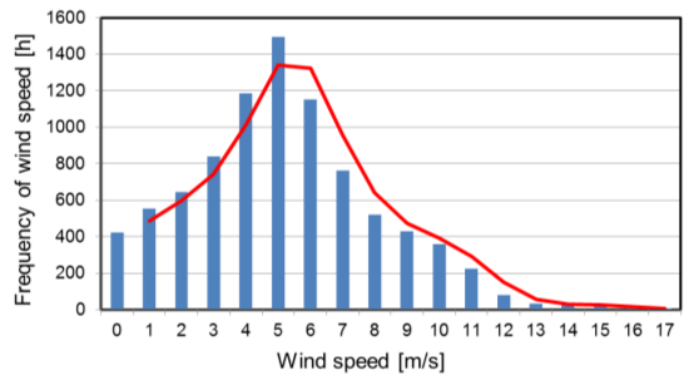

Figure 4: Wind speed distribution throughout the year

The wind resource during this period has an overall mean wind speed of 5.14 meters per second. The highest mean wind speed over an hourly span was 7.62 meters per second. The previous figure shows the wind speed distribution at Tuktoyaktuk village. This distribution is generated from the wind resource data input and can be characterised by four factors:

- The Weibull shape factor $(K)$ : This factor measures the distribution of wind speed over a year. The value of $K$ is taken 1.81 in this study.

- The autocorrelation factor: This factor measures the randomness of the wind. Higher values indicate that the wind speed in 1 hour tends to depend strongly on the wind speed in the previous hour [16]. Lower values mean that the wind speed tends to fluctuate in a more random fashion from hour to hour. The autocorrelation factor value is taken as 0.926 .

- The diurnal pattern strength: This factor measures the wind speed variation over a day. It shows strongly the wind speed depends on the time of day [16]. Higher values indicate that there is a strong dependence on the time of the day. In this study, 0.07 is used.

- The hour of peak wind speed: It is simply the time of day tends to be windiest on an average throughout the year. In this study, 17 is used as the hour of peak wind speed.

Figure 3 shows that there are 17 hours of peak wind speed. The wind speed variation over a day is 0.25 and the randomness in wind speed (autocorrelation factor) is 0.85 .

Figure 4 shows that the most probable wind speed range $2-8 \mathrm{~m} / \mathrm{s}$, occurs approximately $70 \%$ of time. However, the high value of wind speed above this occurs only for limited period of time. This shows the site to be appropriate for wind power production, especially with application of low speed wind turbine.

\section{Wind Turbine}

HOMER has the data for a various manufacturers of wind turbines and their sizes already built into the program. For this simulation, several types of wind turbines have been studied such as: Enercon-E33, Fuhrländer100, Fuhrländer250, NorthenPower100 and WES 30 (Figure 5).
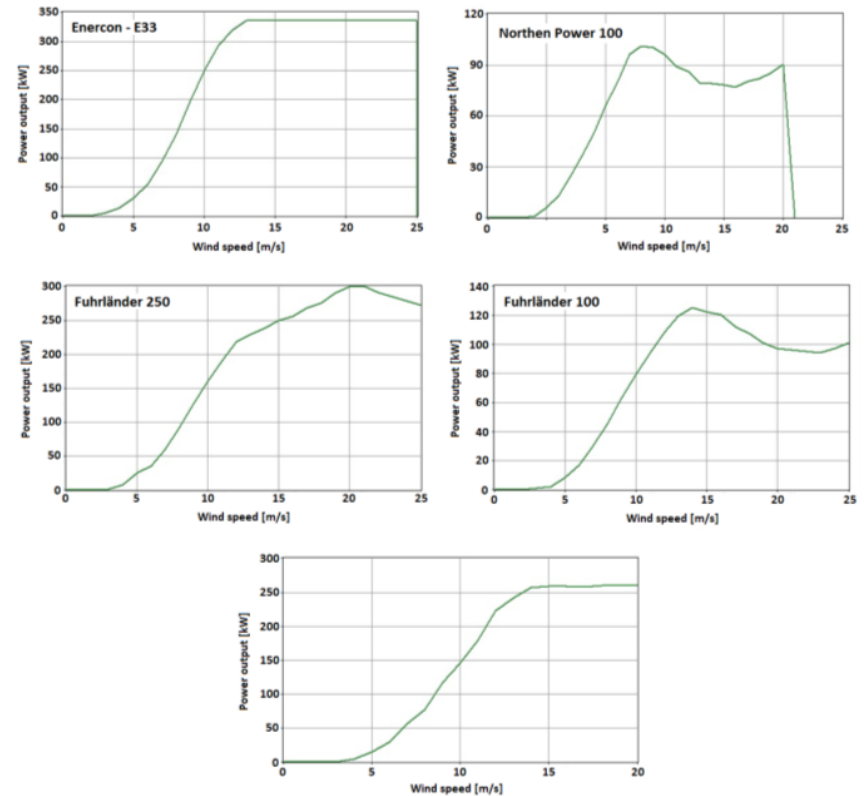

Figure 5: Power curves of five technologies of wind turbines 
Enercon-E33 wind turbine was chosen for the size of its rated output $(330 \mathrm{~kW})$. A wind turbine of this size is typical for a wind-diesel-battery hybrid system with a $851 \mathrm{~kW}$ peak load. Moreover, the power curve of the turbine is very specific because the power generated increases rapidly with the wind speeds and reaches the rated power at a speed of $12 \mathrm{~m} / \mathrm{s}$ and stays stable at very high wind speed compared to other turbines. Thus, Enercon-E33 is characterized by a high power at low wind speeds which makes it advantageous for the case of Tuktoyaktuk.

TABLE 1: Results OF SIMULATION RESUltS OF THE CASE OF WIND-DIESEL WITHOUT ENERGY STORAGE

\begin{tabular}{|c|c|c|c|c|c|c|}
\hline $\begin{array}{l}\text { Wind } \\
\text { turbine }\end{array}$ & $\begin{array}{l}\text { Rated power } \\
\text { (kW) }\end{array}$ & Quantity & $\begin{array}{l}\text { Wind energy } \\
\text { production } \\
\text { (kWh) }\end{array}$ & $\begin{array}{l}\text { Fraction of } \\
\text { wind } \\
\text { energy (\%) }\end{array}$ & $\begin{array}{c}\text { Energy } \\
\text { cost } \\
\text { (\$/kWh) }\end{array}$ & $\begin{array}{l}\text { Excess } \\
\text { energy } \\
(\mathrm{kWh})\end{array}$ \\
\hline$E-33$ & 330 & 3 & $1,840,020$ & $15 \%$ & 0.578 & $1,173,411$ \\
\hline FL 100 & 100 & 8 & $1,552,419$ & $13 \%$ & 0.592 & 975,926 \\
\hline FL 250 & 250 & 3 & $1,208,774$ & $12 \%$ & 0.586 & 695,677 \\
\hline NP 100 & 100 & 8 & $1,243,942$ & $11 \%$ & 0.6 & 748,983 \\
\hline WES 30 & 250 & 3 & $1,074,283$ & $10 \%$ & 0.59 & 613,971 \\
\hline
\end{tabular}

The results of the techno-economic analysis conducted with HOMER on a wind-diesel hybrid system without storage are presented in the Table 1. As we can see, the obtained results confirm the profitability of the choice of the E-33 wind turbine for Tuktoyaktuk village (minimum cost per kilowatthour: $0.578 \$ / \mathrm{kWh}$ ).

\section{Diesel Generator}

Generally, the ratings of the diesel generator are determined by the load but, currently, three diesel generators are used to supply the village by electricity. Their rated power output is 725,960 and $1.400 \mathrm{~kW}$ despite the load varies between 240 and $850 \mathrm{~kW}$. Preliminary simulation results of the current state in Tuktoyaktuk (Figure 6) show that the most used scenario is to operate the first two diesel generators where the third $(1400 \mathrm{~kW})$ rarely works.

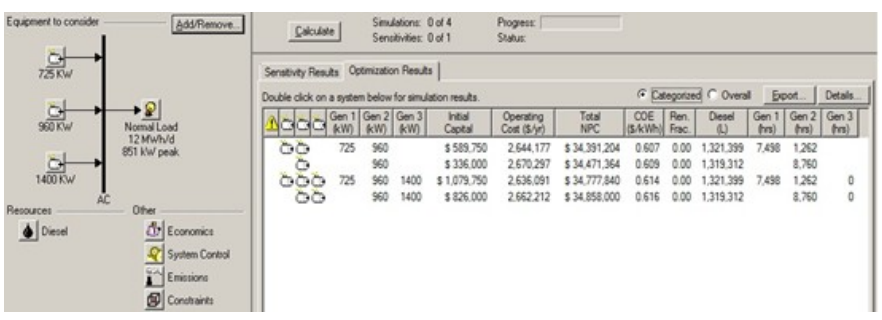

Figure 6: HOMER simulation results of the reference case with different configurations of diesel generators

Other configurations of diesel generators have been proposed and simulated on HOMER in order to optimize the current context of the electricity production in Tuktoyaktuk. HOMER has the data for generic diesel generators built in. However, the results of this analysis, summarized in Table 2, show that the configurations are ineffective and not very attractive without the contribution of renewable sources. Indeed, the best cost of kilowatt-hour obtained with these configurations is \$ 0.694 when two diesel generators of 580 $\mathrm{kW}$ each are used, and the high cost is $0.846 \$ / \mathrm{kWh}$ using three generators of $400 \mathrm{~kW}$ each. For this reason, we have concluded that it is simpler and more efficient to install a single diesel generator supplying the village. This generator's main role is to provide electricity to the village in case of low wind energy penetration rate and during peak periods.

TABlE 2: REsults OF SIMULATION RELATED TO THE DIESEL PLANT CONFIGURATION

\begin{tabular}{|l|c|c|c|}
\hline \multicolumn{1}{|c|}{ Configuration } & $\begin{array}{c}\text { Cost of } \mathbf{k W h} \\
\text { (\$/kWh) }\end{array}$ & $\begin{array}{c}\text { Fuel } \\
\text { consumption } \\
\text { (Litres/year) }\end{array}$ & $\begin{array}{c}\mathbf{C O}_{2} \\
\text { (Kg/an) }\end{array}$ \\
\hline $\mathbf{1 \times 7 2 5 k W ~ \& ~ 1 \times 9 6 0 k W ~}$ & 0.607 & $1,321,399$ & $3,479,678$ \\
\hline $\mathbf{1 \times 9 6 0 k W}$ & 0.609 & $1,319,312$ & $3,439,633$ \\
\hline $\mathbf{2} \mathbf{5 8 0 0 k W}$ & 0.690 & $1,285,766$ & $3,385,844$ \\
\hline $\mathbf{3} \mathbf{4 0 0} \mathbf{k W}$ & 0.846 & $1,567,474$ & $4,127,676$ \\
\hline
\end{tabular}

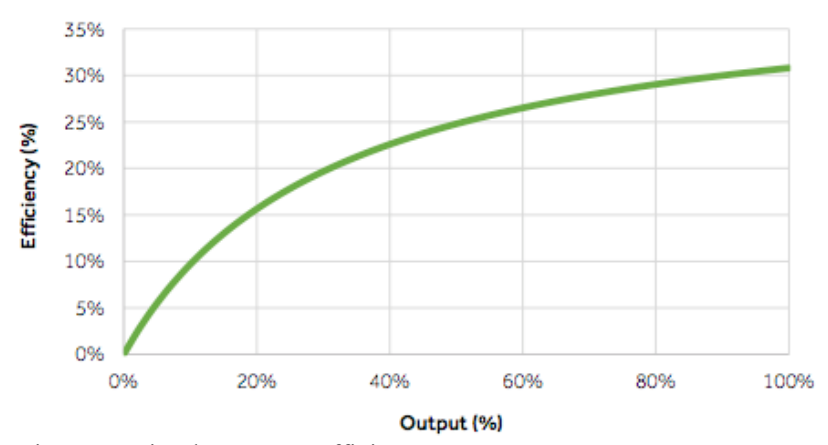

Figure 7: Diesel generator efficiency curve.

Taking into account the operation and maintenance purposes, a diesel generator of $1200 \mathrm{~kW}$ rated power (RP) is used. In this case, the size of the diesel generator has been selected such that it will meet the minimum loading condition in order to avoid low load factor operation and will supply the maximum load $(851 \mathrm{~kW})$ which represents $70 \%$ of the RP of DG. Therefore, $30 \%$ of diesel power are available such as spinning reserve and also can be used to charge the energy storage system (if available). A second generator of the same power must be provided to be used only in the emergency case or if the first generator is out of service. The diesel gensets are supposed to have an operating lifetime of $15,000 \mathrm{~h}$ with a minimum load rate of $30 \%$. Figure 7 shows the efficiency curve relating the fuel consumption to the power output for the diesel gensets. This curve demonstrates two aspects of diesel power plant. Firstly, in general, the efficiency of diesel genset is very low. Indeed, operating at a peak efficiency of around $32 \%, 68 \%$ of the energy supplied to a diesel generator is then wasted in heat. Secondly, there is a pronounced decreasing in efficiency with a reduction in power output. For this reason, a constraint is placed on the system within HOMER to limit the minimal power output of the diesel gensets to $30 \%$ of their overall capacity.

The fuel consumption is modeled in HOMER by a linear curve characterized by a slope and intercept at no load. For a capacity range of $300 \mathrm{~kW}$ (minimal limit) to $1200 \mathrm{~kW}$, the slope and the intercept are $0.215 \mathrm{l} / \mathrm{h} / \mathrm{kW}$ and $0.051 \mathrm{l} / \mathrm{h} / \mathrm{kW}$ respectively.

\section{E. Battery Energy Storage System}

Battery is a storage unit fundamental for storing electrical energy for maximum utilization of intermittent renewable energies [20]. In addition, the main purpose of having a 
battery energy storage system is to minimise the demandgeneration mismatch in the absence of the diesel power plant. The lead-acid battery, often used in RAHES, is the batteries technology chosen for this study. Modeling of lead-acid batteries for real time analysis of RAHES must taking into account the folling parameters: (a) rate of charge/discharge, (b) ambient temperature, (c) battery storage capacity, (d) state of charge, (e) life and other internal phenomenon, such as gassing, double layer effect, self-discharge, heating loss, and diffusion [20].

A battery bank, composed from several identical batteries connected in series and/or parallel, must be sized correctly in order to obtain the desired capacity taking into account the load and the excess energy provided by wind power system.

Considering the profile of the energy consumption and the power curve generated by the wind, it was deduced that the maximum difference between these two profiles is about $696 \mathrm{~kW}$. The preliminary design must provide the installation of a battery bank able to absorb this maximum power.

The type of the batteries used in this study is of 'Trojan L16P ". The technical characteristics of this battery are presented in the figures 8 and 9. It is important to mention that we will need about 6,500 batteries to be able to store completely the maximum excess power because each battery of this type have $6 \mathrm{~V}$ as voltage, $18 \mathrm{~A}$ as current and $360 \mathrm{Ah}$ as individual storage capacity.

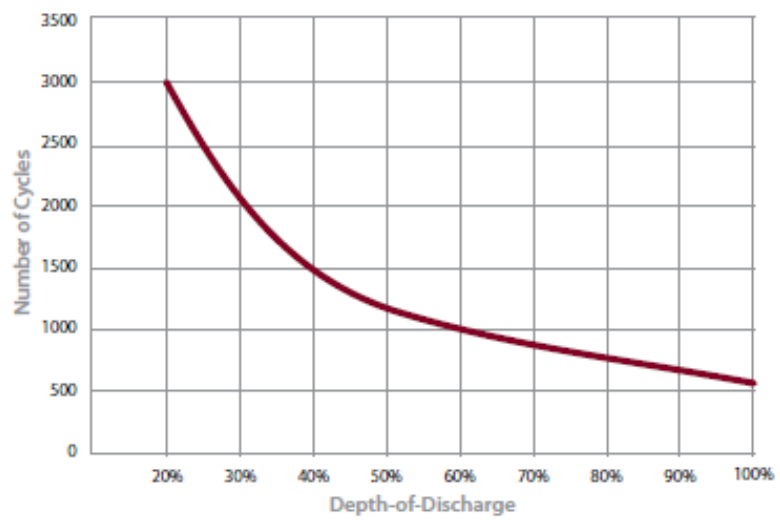

Figure 8: Trojan L16P performance [21]

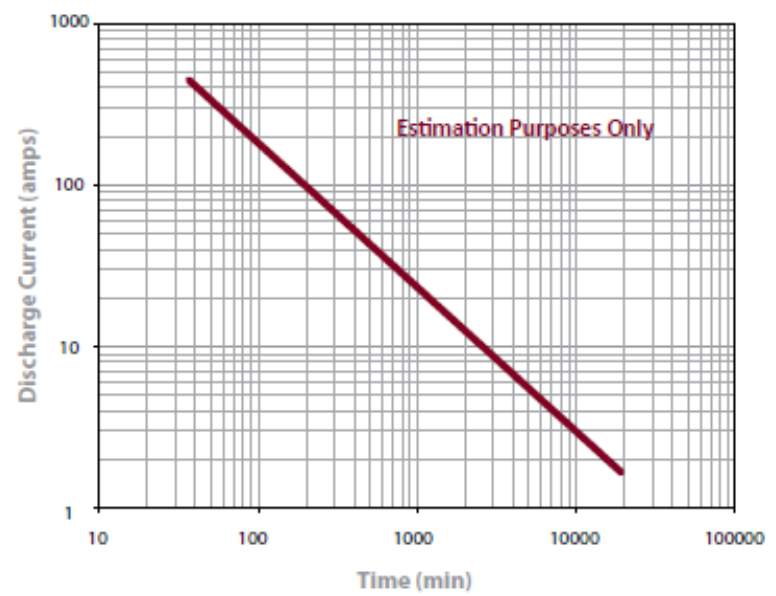

Figure 9: Typical cycle life in a stationary application [21]
The final outcome of preliminary selection of the components of the wind-diesel-battery hybrid system (WDBHS) is presented in the Table 3. The simulation results of this configuration are presented in the Table 4.

TABLE 3: COMPONENTS OF THE PRELIMINARY CONFIGURATION

\begin{tabular}{|l|c|c|}
\hline \multicolumn{1}{|c|}{ Equipment } & Capacity (kW) & Quantity \\
\hline Enercon E-33 & 330 & 3 \\
\hline Diesel generator & 1,200 & 2 \\
\hline Power converter & 700 & 1 \\
\hline Batteries - Trojan L16P & 0.108 & 6,500 \\
\hline
\end{tabular}

TABLE 4: RESULTS OF THE PRELIMINARY CONFIGURATION OF THE WDBHS

\begin{tabular}{|c|c|}
\hline Description & Value \\
\hline Investment (\$) & $\$ 3,821,500$ \\
\hline Price of kWh $(\$ / k W h)$ & 0.535 \\
\hline Fraction of renewable energy (RE) (\%) & $22 \%$ \\
\hline Fuel consumption (Liters) & $1,024,371$ \\
\hline Operation time of the $1^{\text {st }}$ diesel generator $(\mathrm{hr})$ & 3,046 \\
\hline Operation time of the $2^{\text {nd }}$ diesel generator $(\mathrm{hr})$ & 0 \\
\hline Excess Energy (kWh) & 96,784 \\
\hline Emissions ( $\mathrm{Kg} \mathrm{CO}_{2} /$ year) & $2,697,507$ \\
\hline
\end{tabular}

These results show that the excess energy dissipated without useful utilisation has largely decreased (by approximately $91.75 \%$ ) compared to the scenario of winddiesel without storage, which certainly increases the profitability of the project. However, it is possible to further optimize the WDBHS performance by acting on the configuration of the system. The optimization scenario will be presented in the followed sections.

\section{OptIMIZATION OF WDBHS}

\section{A. First optimization scenario}

A preliminary optimization was conducted by modifying the important variables such as the number of wind turbines and the number of batteries in order to determine the best configuration based on the cost of the produced $\mathrm{kWh}$. The obtained results are shown in the Tables 5 and 6 . It is to note that the number of diesel generators has not changed compared to the primary configuration.

TABLE 5: COMPONENTS OF THE BEST CONFIGURATION BASED ON THE FIRST OPTIMIZATION SCENARIO

\begin{tabular}{|l|c|c|}
\hline \multicolumn{1}{|c|}{ Equipment } & Power (kW) & Quantity \\
\hline Enercon E-33 & 330 & 10 \\
\hline Diesel generator & 1,200 & 2 \\
\hline Power convertor & 700 & 1 \\
\hline Batteries - Trojan L16P & 0.108 & 8,000 \\
\hline
\end{tabular}

TABLE 6: SimUlation RESUltS OF THE BEST CONFIGURATION OF THE WDBHS BASED ON THE FIRST OPTIMIZATION SCENARIO

\begin{tabular}{|c|c|}
\hline Description & Value \\
\hline Investment (\$) & $\$ 7,095,000$ \\
\hline Price of kWh $(\$ / k W h)$ & 0.424 \\
\hline Fraction of renewable energy (RE) (\%) & $60 \%$ \\
\hline Fuel consumption (Liters) & 529,667 \\
\hline Operation time of the $1^{\text {st }}$ diesel generator $(\mathrm{hr})$ & 1,606 \\
\hline Operation time of the $2^{\text {nd }}$ diesel generator $(\mathrm{hr})$ & 0 \\
\hline Excess Energy (kWh) & $2,903,407$ \\
\hline Emissions ( $\mathrm{Kg} \mathrm{CO}_{2} /$ year) & $1,394,787$ \\
\hline
\end{tabular}

From the results presented in the Tables 5 and 6 , a significant reduction, about $20 \%$, can be observed on the cost of produced $\mathrm{kWh}$ which decreases from $0.535 \$ / \mathrm{kWh}$ to 
$0.424 \$ / \mathrm{kWh}$. Also, a radical rise in the fraction of renewable energy (i.e. wind energy penetration rate) and in the excess energy (i.e. dissipated energy) was also noted. This is due to the large number of turbines used in this scenario. The storage capacity could then increase to be able to absorb the all excess energy, but it would increase the investment cost, and therefore the cost of produced energy $(\$ / \mathrm{kWh})$.

Moreover, by analysing the costs of the system, an increasing about $85 \%$ of the investment cost, equivalent to $3,273,500 \$$, can be observed compared to the preliminary selection of components of the hybrid system. Hence the need for an intermediate solution taking into account the impact of the investment part in the total cost of the system should be investigated.

\section{B. Second optimization scenario}

The development of this solution needs to take into account the cost per $\mathrm{kWh}$ and the investment cost. These two factors are the key element with other secondary factors, in determining the profitability of wind-diesel-battery hybrid system (WDBHS) [22-25].

We conducted tens simulations of WDBHS with a number of wind turbines varying between 2 and 10. The purpose was to observe variations in investment costs and of the $\mathrm{kWh}$, and the saving achieved compared to the baseline scenario. The obtained results are shown in Table 7 and figures 10 and 11.

TABlE 7: Simulation RESUltS OF THE BEST CONFIgURATION OF THE WDBHS BASED ON THE FIRST OPTIMIZATION SCENARIO

\begin{tabular}{|c|c|c|c|c|}
\hline $\begin{array}{c}\text { Number of used } \\
\text { wind turbines }\end{array}$ & Investment (\$) & $\begin{array}{c}\text { Fuel consumption } \\
\text { (L) }\end{array}$ & $\mathbf{\$} / \mathbf{k W h}$ & Saving (\%) \\
\hline 2 & $\$ 3,011,000$ & $1,179,446$ & 0.584 & $4.3 \%$ \\
\hline 3 & $\$ 3,596,500$ & $1,027,839$ & 0.532 & $12.8 \%$ \\
\hline 4 & $\$ 4,182,000$ & 906,314 & 0.496 & $18.7 \%$ \\
\hline 5 & $\$ 4,617,500$ & 816,492 & 0.471 & $22.8 \%$ \\
\hline 6 & $\$ 5,203,000$ & 726,736 & 0.452 & $25.9 \%$ \\
\hline 7 & $\$ 5,488,500$ & 686,448 & 0.443 & $27.4 \%$ \\
\hline 8 & $\$ 6,524,000$ & 589,377 & 0.433 & $29.0 \%$ \\
\hline 10 & $\$ 6,809,500$ & 549,926 & 0.425 & $30.3 \%$ \\
\hline
\end{tabular}

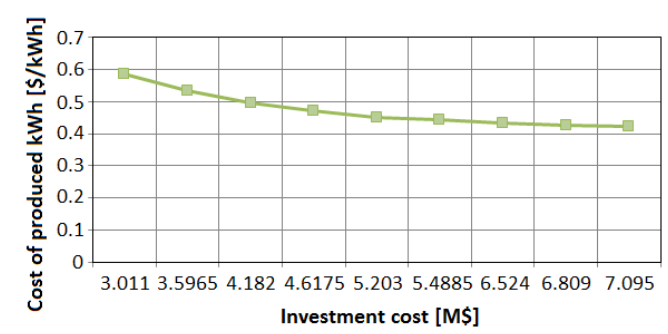

Figure 10: Variation of the cost of produced $\mathrm{kWh}$ with the investment cost

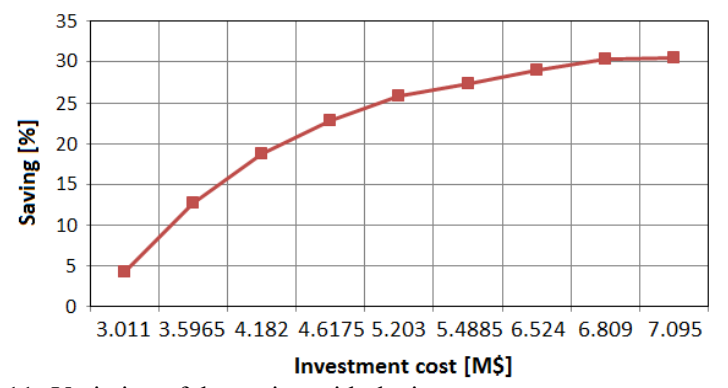

Figure 11: Variation of the saving with the investment cost

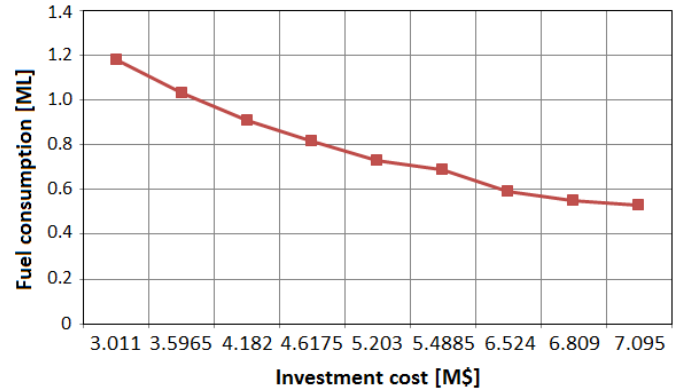

Figure 12: Variation of the fuel consumption with the investment cost

The curves shown in figures 10 and 11 are characterized by two sections. The first is transitory and the second is quasilinear. During the transitory phase, the cost of $\mathrm{kWh}$ and saving vary widely with the investment cost (IC), but beyond this phase, the variation becomes minimal (at very high investment). Thus, it would be wise to choose the number of wind turbines in order to correspond to the transitional phase where a compromise can be obtained between a best saving and minimal costs of investment and produced $\mathrm{kWh}$.

Other important information is the annual fuel consumption of the diesel generators. As shown in figure 12, the fuel consumption decreases quasi-linearly with the investment cost. Then, the ratio (fuel consumption/investment) is indifferent compared to the results presented in the figures 10 and 11 . We need to increase the installed wind power capacity if we want to reduce the use of the diesel generators. A compromise must, also, be founded between saving of fuel consumption and cost investment.

\section{CONCLUSION}

The renewable energy systems have intermittent output characteristics and are integrated with conventional power sources to deliver a stable power output. In various hybrid energy systems, diesel genset (DG) acts as steady source of power. The DG systems are designed to supply the load and also charge the battery energy storage system, if the renewable energy source along with battery is unable to supply the load.

A particular objective of this study was to show that where wind and solar resources are available, this system is able to developing and acting specifically in remote areas.

It was shown from the simulation results that the obtained optimal configuration of a hybrid energy system could overcome the effect of the meteorological and logistic conditions on the reliable supply of the village.

In the case of Tuktoyaktuk village, the simulations results prove that the best solution to reliable load supply without interruption and with minimum investment cost is the combination of a diesel generator with the hybrid wind-battery system (WDBHS) used ten wind turbines of Enercon-E33 and two diesel generator. This combination allows a fuel saving about $30 \%$.

\section{REFERENCES}

[1] S. Rehman, I.M. El-Amin, F. Ahmad, S.M. Shaahid, A.M. AlShehri, J.M. Bakhashwain, A. Shash,2007. Feasibility study of hybrid retrofits to an isolated off-grid diesel power plant.. 
[2] L. H Tay, W. W. L. Keerthipala and L. J Borle, " Performance analysis of a wind/diesel/battery hybrid power system", Australasian Universities Power Engineering Conference, Perth, Australia, 23-26 Sept. 2001, pp. 107 - 112.

[3] N. Mendis, K. Muttaqi, S. Sayeef and S. Perera, "Power generation in isolated and regional communities: Application of a doubly-fed induction generator based wind turbine", 19th Australasian Universities Power

[4] N. Mendis, K. M. Muttaqi, S. Sayeef, S. Perera. Operation of a Wind-Diesel-Battery based Hybrid Remote Area Power Supply System. 6th International Conference on Electrical and Computer Engineering ICECE 2010, 18-20 December 2010, Dhaka, Bangladesh.

[5] Pragya Nema, R.K. Nema and Saroj Rangnekar, 2009. A current and future state of art development of hybrid energy system using wind and PV-solar: A review.

[6] Renewable and Sustainable Energy Reviews, 13(8):2096- 2103.

[7] Hongxing Yang, Zhou Wei, Lou Chengzhi, 2009. Op=mal design and techno-economic analysis of a hybrid solar- wind power generation system. Applied Energy, 86(2):163-169.

[8] Wei Zhou, Hongxing Yang, Zhaohong Fang, 2008. BaNery behavior prediction and battery working states analysis of a hybrid solar-wind power generation system. Renewable Energy, 33(6):1413-1423.

[9] S. Diaf, M. Belhamel, M. Haddadi, A. Louche, 2008.Technical and economic assessment of hybrid photovoltaic/wind system with battery storage in Corsica Island. Energy Policy, 36(2):743-754.

[10] Ali Naci Celik, 2003. Techno-economic analysis of autonomous PV-wind hybrid energy systems using different sizing methods. Energy Conversion and Management; 44(12):1951-1968.

[11] E. Muljadi and J.T. Bialasiewicz,"Hybrid power system with a controlled energy storage", IEEE Ind, Electron. Soc. Annu. Meeting Conf, Virginia, USA, vol. 2, 2-6 Nov. 2003, pp. 1296 1301 .

[12] E. Muljadi and J.T. Bialasiewicz,"Hybrid power system with a controlled energy storage", IEEE Ind, Electron. Soc. Annu. Meeting Conf, Virginia, USA, vol. 2, 2-6 Nov. 2003, pp. 1296 1301.

[13] L. Wei and G. Joos, “A Power Electronic Interface for a Battery Supercapacitor Hybrid Energy Storage System for Wind Applications", Power Electronics Specialists Conference, Rhodes, Greece, 15-19 Jun.

[14] Murdoch University, 2009.

[15] HOMER.

[16] A. Salmani, S. Sadeghzadeh, M.R. Naseh. Optimization and Sensitivity Analysis of a Hybrid System in Kish-Iran. International Journal of Emerging Technology and Advanced Engineering. Volume 4, Issue 1, January 2014.

[17] N. Mahmud and a. Hassan "Modeling and Cost Analysis of Hybrid Energy System for St. Martin Island Using HOMER" Informatics, Electronics \& Vision (ICIEV), 2013 International Conference

[18] Lambert, T., Gilman, P., Lilienthal, P. (2005) 'Micro-power System modelling with Homer', in Farret, F.A., Godoy Simões, M. (eds), Integration of alternative sources of energy, pp. 379 - 417

[19] R. Sen. Off-grid electricity generation with Renewable Energy Technologies in India: An application of HOMER. MSc. Renewable Energy \& Environmental Modelling University of Dundee. September 2011.

[20] L. Olatomiwa, S. Mekhilef, A. S. N. Huda, K. Sanusi. Technoeconomic analysis of hybrid PV-diesel-battery and PV-winddiesel-battery power systems for mobile BTS: the way forward for rural development. Energy Science \& Engineering published by the Society of Chemical Industry and John Wiley \& Sons Ltd. March 2015.

[21] Trojan Battery Company.

[22] G. El-Jamal, M. Ghandour, H. Ibrahim, A. Assi. Technical feasibility study of solar-pumped hydro storage in Lebanon. IEEE, International Conference on Renewable Energies for Developing Countries 2014 (REDEC 2014), pp. 23-28, Beirut, Lebanon, 26-27 Nov. 2014.

[23] G. El-Jamal, H. Ibrahim, M. Ghandour. Investigation of the Technical-Economic Contribution of Renewable Energy and
Energy Efficiency: Lebanese Context. IEEE, International Conference on Renewable Energies for Developing Countries 2014 (REDEC 2014), pp. 174-179, Beirut, Lebanon, 26-27 Nov. 2014.

[24] G. El-Jamal, M. Ghandour, H. Ibrahim. Application of multicriteria decision-methods for the selection of renewable energy sources, Lebanese case study. 2nd International Conference Efficient Building Design: Materials and HVAC Equipment Technologies, Beirut, Lebanon, September 22-23, 2016.

[25] G. El-Jamal, H. Ibrahim, M. Ghandour. Integration of Energy Storage in a Wind-Diesel Hybrid System - Techno economical \& Operational Advantages. International Conference on Renewable Energies for Developing countries (REDEC), Beirut, Lebanon, 1315 July 2016. 